\title{
The impact of comorbidity on medication adherence and therapeutic goals
}

\author{
A Corsonello ${ }^{1 *}$, C Pedone ${ }^{2,3}$, S Garasto ${ }^{1}$, G Maiuri ${ }^{1}$, A Carelli ${ }^{1}$, C Zottola ${ }^{1}$, F Lattanzio ${ }^{4}$ \\ From de Senectute: Age and Health Forum \\ Catanzaro, Italy. 5-7 December 2009
}

\section{Introduction}

Prescribing medications is often challenging in older people with multiple chronic diseases. Non-adherence to prescribed medications is among the most important problems, so that many people are not benefiting properly from the drugs they are prescribed. Additionally, this also represents a costly waste for health services [1].

\section{Comorbidity and medication adherence}

Poor adherence to the prescribed therapy is highly prevalent in older patients. Prevailing evidence suggests that age per se should not be considered as a risk factor for poor adherence [2]. Lower educational level, less affluent economic status, cognitive/physical impairment, being assisted by foreign caregivers, and some chronic diseases, such as chronic renal failure, are commonly reported poorly modifiable correlates of non-adherence. Regimen complexity represents a to some extent modifiable correlate [2]. Vision impairment, reduced manual dexterity, and patients' perception of medication importance may contribute to determine the relationship between regimen complexity and non-adherence. There is minimal evidence to support interventions that improve medication adherence, and the effects of psychosocial interventions are largely unknown [1].

\section{Therapeutic goals in patients with multiple chronic conditions}

Patients with multiple chronic conditions may vary in regard to their opinion about health outcomes such as longer survival, prevention of disease-specific events, physical and cognitive function, and tolerable risk of adverse drug reactions. A paradigmatic example of how challenging this issue can be in clinical practice is the difficulty in rational prescribing for older patients with

${ }^{1}$ Istituto Nazionale di Ricovero e Cura per Anziani (INRCA), Cosenza, Italy multiple chronic conditions and reduced life expectancy, when the likelihood of benefit and goals of care must also be considered in addition to satisfying the basic principles of optimal medication use in the elderly [3].

\section{Author details}

${ }^{1}$ Istituto Nazionale di Ricovero e Cura per Anziani (INRCA), Cosenza, Italy. ${ }^{2}$ Università Campus BioMedico, Rome, Italy. ${ }^{3}$ Fondazione Alberto Sordi Onlus, Rome, Italy. ${ }^{4}$ Istituto Nazionale di Ricovero e Cura per Anziani (INRCA), Ancona, Italy.

Published: 19 May 2010

\section{References}

1. Williams A, Manias E, Walker R: Interventions to improve medication adherence in people with multiple chronic conditions: a systematic review. J Adv Nurs 2008, 63(2):132-143.

2. Corsonello A, Pedone C, Lattanzio F, Lucchetti M, Garasto S, Carbone C, Greco C, Fabbietti P, Incalzi RA: Regimen complexity and medication nonadherence in elderly patients. Ther Clin Risk Manag 2009, 5(1):209-216.

3. Holmes HM: Rational prescribing for patients with a reduced life expectancy. Clin Pharmacol Ther 2009, 85(1):103-107.

doi:10.1186/1471-2318-10-S1-L21

Cite this article as: Corsonello et al:: The impact of comorbidity on medication adherence and therapeutic goals. BMC Geriatrics 2010 10(Suppl 1):L21.
Submit your next manuscript to BioMed Central and take full advantage of:

- Convenient online submission

- Thorough peer review

- No space constraints or color figure charges

- Immediate publication on acceptance

- Inclusion in PubMed, CAS, Scopus and Google Scholar

- Research which is freely available for redistribution

Submit your manuscript at www.biomedcentral.com/submit
C Biomed Central 